\title{
Experimental Investigation of Air-Silicone Oil Slug Flow Development around a Horizontal 90 Degree Bend
}

\author{
Rajab Omar, Buddhika N. Hewakandamby \\ Department of Chemical and Environmental Engineering, Faculty of Engineering, the University of Nottingham \\ Nottingham NG7 2RD, United Kingdom \\ ezzro@exmail.nottingham.ac; enzbnh@exmail.nottingham.ac
}

\begin{abstract}
An experimental investigation of slug flow around $90^{\circ}$ horizontal bend is presented. This paper demonstrates the visual observations during the onset of hydrodynamic slugs. It also presents the axial development of slug flow downstream a horizontal $90^{\circ}$ bend. The available slug flow correlations are tested against the experimental results. Air-Silicone oil (viscosity $5 \mathrm{mPa} . \mathrm{s}$ ) experiments were conducted in a horizontal test section of a $68 \mathrm{~mm}$ ID. The behaviour of slug characteristics was studied at 5D upstream and four locations (10D, 40D, 69D and 75D) downstream of the bend using ECT and WMS. The flow around the bend was observed using a high speed imaging system. This work demonstrates that at low gas flow rate hydrodynamic slug flow is mainly generated from the Kelvin-Helmholtz instability. While at high gas superficial velocities $(>2.29 \mathrm{~m} . \mathrm{s}-1)$, slugs are developed from the coalescence of roll waves travelling at different velocities. Horizontal $90^{\circ}$ bends have inconsiderable effects on the behaviour of slugs. This is due to that the phase separation and momentum transfer being insignificant. The horizontal bend has a minimum influence on the velocity and frequency of the flow structure.
\end{abstract}

Keywords: WMS, ECT, Slug Flow, Flow Development, 90 Degree Bends.

\section{Introduction}

Slug flow is a common phenomenon that occurs in the majority of industrial applications, over a wide range of liquid and gas flow rates. In horizontal pipes, slug flow is characterised by a repeated pattern of aerated liquid mass occupying the pipe separated by a gas mass occupying the pipe partially in a wavy stratified configuration. Slugging phenomenon is categorised, based on the formation mechanism, into two main types; hydrodynamic slugging and terrain slugging. Hydrodynamic slugging is the common slug flow pattern that occurs in straight pipes due to a growing disturbance over a stratified interface. This type of slugs is short and high in frequency. Terrain induced slugging is more complex and transient flow that forms by the accumulation of liquid phase at the bottom of a pipeline that passes through a hilly terrain. The pressure upstream of the liquid bridge continuously increases to the point that it blows the liquid along the pipeline forming a long slug. The transient behaviour of slug flow is usually associated with undesired fluctuations in the pressure drop and flow rate. $[1,2]$.

Slug flow in straight pipes has been studied extensively over the last decades. Several theoretical models have been developed in order to provide a reliable estimate to the complex behaviour of liquid slugs [3, 4]. They main hydrodynamic parameters of slug flow have been continuously investigated over years. Several empirical correlations and semi-empirical models have been proposed to predict the characteristics of slugs. The performance of these correlations at a wide range of operation conditions is being challenged.

The pipeline system in oil and gas industries consists of risers, horizontal and inclined pipes, in addition to fittings such as bends and T-junctions. This can make slugging phenomenon even more complex and unpredicted. Therefore the occurrence of slug flow, in such pipelines, is a fundamental challenge in terms of the damage that can cause at pipe fittings due vibration and the generation of dryout zones. Moreover, predicting the size of slugs is a crucial factor in equipment designed and control, particularly gas-liquid separators due to the continuous change in the volume of liquid and gas received at the vessel.

The effects of obstructions and fittings such as bends, on the evolution of slug flow, have been only investigated in a limited number of publications. Moreover; those publications that considered slug characteristics through bends were mostly conducted in relatively small pipes and with water as liquid phase. Therefore, this work aims to investigate the 
effects of a horizontal $90^{\circ}$ bend on the evolution of slug flow in $68 \mathrm{~mm}$ ID pipes. This paper presents comprehensive experimental results of air-silicone flows through a horizontal $90^{\circ}$ bend. It provides more detailed analysis of slug characteristics before and after the bend in order to evaluate the significance of horizontal $90^{\circ}$ bends on flow alteration.

\section{Methodology and Instrumentations}

The experimental rig used in this work was built primarily to investigate the evolution of gas-liquid flow through vertical and horizontal $90^{\circ}$ bends in series. A schematic diagram of the flow rig is illustrated in Fig. 1. It consists of a storage tank, a liquid centrifugal pump, mixing section, a riser of $4.5 \mathrm{~m}$ long, two horizontal sections of $9.2 \mathrm{~m}$ and $5.5 \mathrm{~m}$ long respectively and two $90^{\circ}$ bends. In this work only the horizontal bend was employed. The experiments were conducted in a horizontal test section that consist of two horizontal pipes of $9.2 \mathrm{~m}$ and $5.5 \mathrm{~m}$ long respectively with a $90^{\circ}$ bend of curvature ratio $R / D=3$ (where $R$ and $D$ represent the radius of the bend and the pipe diameter respectively) in between. The test sections are made of acrylic pipes with an average internal diameter of $68 \mathrm{~mm}$. The air and silicone oil flow rates were varied from 0.36 to $3.21 \mathrm{~m} . \mathrm{s}^{-1}$ and 0.22 to $0.53 \mathrm{~m} \cdot \mathrm{s}^{-1}$ respectively generating a total of 40 slug flow conditions. During the experiments, the two-phase mixture passes through a $4.5 \mathrm{~m}$ riser and a vertical upward $90^{\circ}$ bend before it reaches the horizontal test section. The gas-liquid mixture is returned to the storage tank, through the return section, where the phase separation occurs. The air is vented to the atmosphere while the silicon oil is drained down to the storage tank under the gravity effect.

Electrical Capacitance tomography (ECT) and Wire Mesh Sensor (WMS) were used to obtain real-time phase distribution measurements. The ECT was located at 5D upstream of the bend, while the WMS is moved at 10D, 40D, 69D and 75D downstream of the bend. Experiments at different locations were done separately, though the repeatability of the measurements at upstream of the test section is justified through random uncertainty analysis and PDF plots. A direct comparison between the WMS and ECT indicated that the void fraction measurements of both devices are in good agreement with an average relative percentage error of 5\% and standard deviation of 1.02

The flow patterns were identified through visual observations with the assistance of high-speed imaging. The void fraction data was used to estimate slug flow characteristics such as slug frequency, slug velocity and gas holdup in liquid slug. The experimental results were used to evaluate the performance of several slug flow correlations; the predictions of those correlations were compared at before and after the bend.

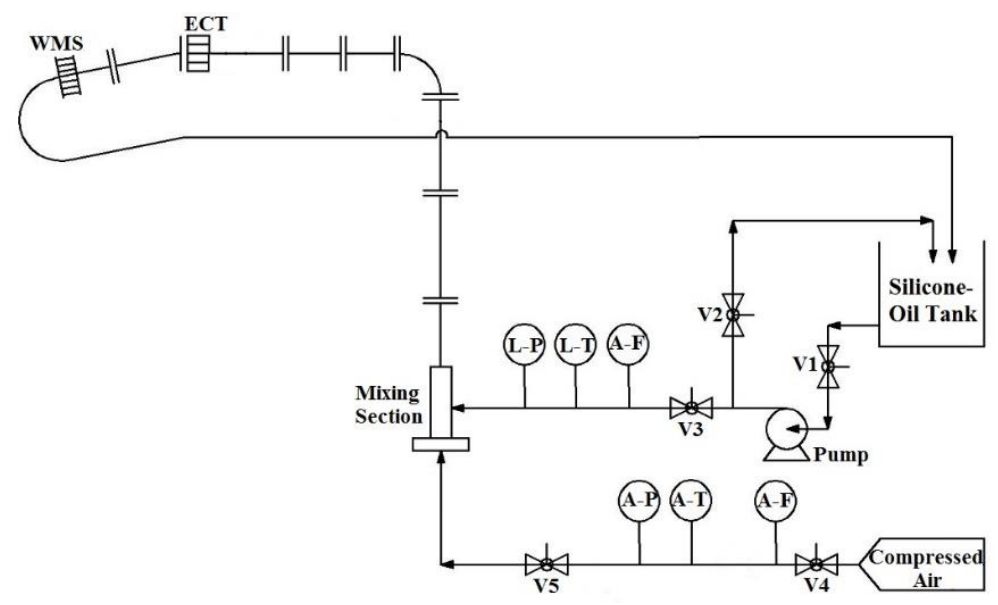

Fig. 1: A schematic diagram of the flow rig.

\section{Results and Discussion}

\subsection{Visual Observations}

In this work, hydrodynamic slugging was observed over a range of gas and liquid superficial velocities of $0.36 \mathrm{~m} . \mathrm{s}^{-1}$ to $3.21 \mathrm{~m} . \mathrm{s}^{-1}$ and $0.15 \mathrm{~m} . \mathrm{s}^{-1}$ to $0.53 \mathrm{~m} . \mathrm{s}^{-1}$ respectively. Disturbance waves and roll waves as described by [5] were also observed intermittently. At high gas flow rate and low liquid flow rate a short and foamy slugs are observed similar to the undeveloped slugs described by [6]. Fig. 2 shows the observed liquid structures. 


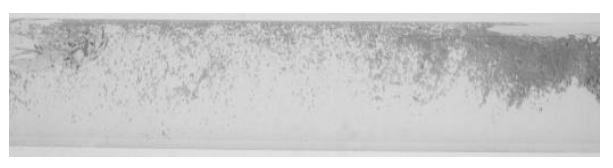

(a) $\mathrm{U}_{\mathrm{gs}}=0.55 \mathrm{~m} / \mathrm{s}, \mathrm{U}_{\mathrm{ls}}=0.45 \mathrm{~m} / \mathrm{s}$

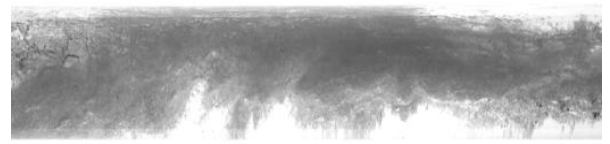

(c) $\mathrm{U}_{\mathrm{gs}}=3.21 \mathrm{~m} / \mathrm{s}, \mathrm{U}_{\mathrm{ls}}=0.45 \mathrm{~m} / \mathrm{s}$

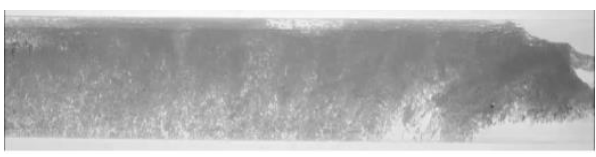

(b) $\mathrm{U}_{\mathrm{gs}}=3.21 \mathrm{~m} / \mathrm{s}, \mathrm{U}_{\mathrm{ls}}=0.15 \mathrm{~m} / \mathrm{s}$

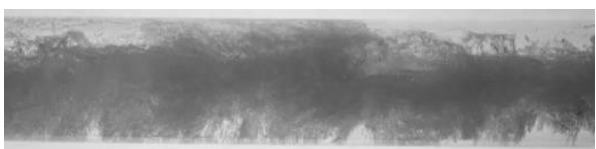

(d) $\mathrm{U}_{\mathrm{gs}}=2.29 \mathrm{~m} / \mathrm{s}, \mathrm{U}_{\mathrm{ls}}=0.15 \mathrm{~m} / \mathrm{s}$

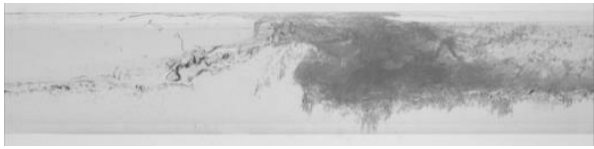

(e) $\mathrm{U}_{\mathrm{gs}}=2.99 \mathrm{~m} / \mathrm{s}, \mathrm{U}_{\mathrm{ls}}=0.15 \mathrm{~m} / \mathrm{s}$

Fig. 2: Slug flow and disturbance waves observed during the experiments.

Slug flow was found to originate directly from long waves as suggested by Kelvin-Helmholtz stability analysis for gas superficial velocity below $2.29 \mathrm{~m} . \mathrm{s}^{-1}$. At high gas superficial velocities $\left(>2.29 \mathrm{~m} \cdot \mathrm{s}^{-1}\right)$, the slug formation mechanism seems to be similar to that reported by [7]. The Kelvin-Helmholtz waves are generated over the interface. These waves travel at different velocities and seemed to overtake each other and rapidly evolve to form a slug. At these conditions, slugs cannot from directly from the growth of the roll wave and the coalescence of consecutive waves is required to supply enough liquid to bridge the pipe. The slugs generated with this mechanism are very fast and highly aerated. It was not easy to capture the whole process due to the high speed of the flow and the limited focal length of the camera lens used.

Another noteworthy observation is reported in Fig. 3. The figure shows the effect of the generated slugs on the downstream waves. Eight frames are extracted sequentially at a time interval of around 1/100 s, from a high seeped video that captures the flow in a pipe length of around $20 \mathrm{~cm}$. Frames ( $a$ and $b$ ) illustrate the growth of the wave as it moves downstream from left to right. The wave suddenly jumps to block the pipe, immediately after the initiation of unseen slug from the left side of the frames. Frames ( $c$ and d) show the growing wave and the foamy front of the upstream slug. Shortly afterwards the downstream slug propagates further forming a longer liquid bridge while the upstream slug comes to appearance as in (e and $\mathrm{f}$ ).

It is noticeable that an aerated region is trapped between the upstream slug and the newly formed slug downstream. As the flow propagates downstream, the two slugs are expected to merge. This observation suggests that the formation of slug may influence the wave growth upstream. This is mainly due to a sudden decrease in pressure and consequently an increase in the suction force in the region downstream of the slug. 
(a)

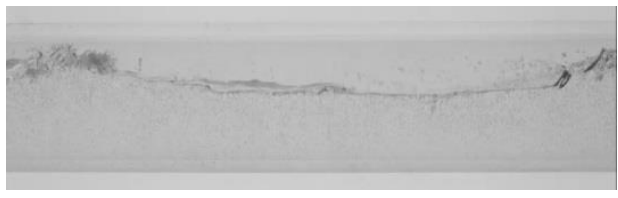

(b)

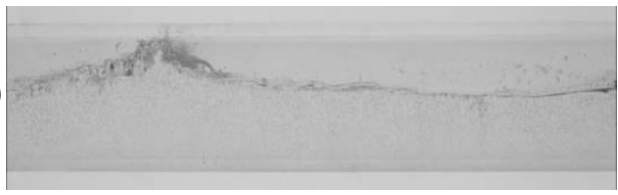

(c)

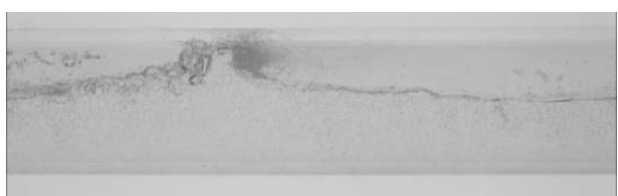

(d)

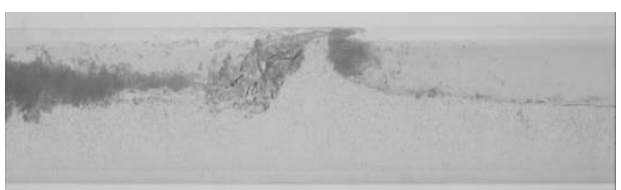

(e)

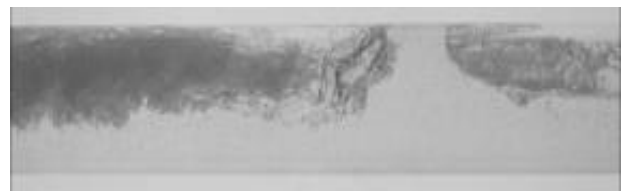

(f)

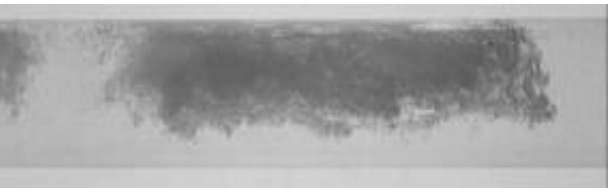

$(\mathrm{g})$

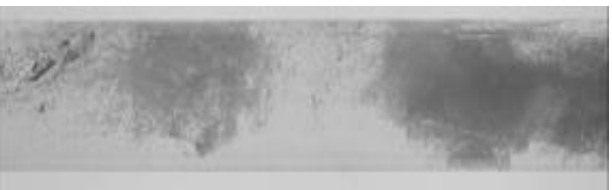

(h)

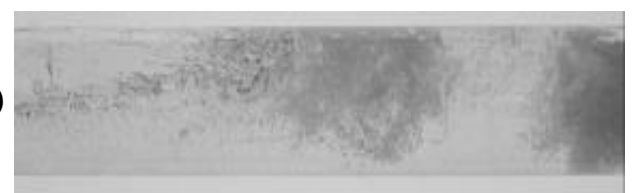

Fig. 3: Photographs illustrating the onset of a slug at; Uls=0.45m.s-1, Ugs=1.37m.s-1. The direction of the flow from left to right.

\subsection{Void Fraction in Liquid Slug}

Fig. 4 illustrates that the gas holdup in liquid slug remains almost constant along the pipeline particularly at low gas superficial velocities. The vertical dashed line corresponds to the location of the bend. The void fraction is expected to increase after the bend due to gas expansion, though; it was only the case at low gas flow rate. In fact, at high gas flow rates, the void fraction was slightly higher at upstream of the bend than that of downstream. This is possibly due to that undeveloped liquid slugs often do not persist to downstream of the bend.

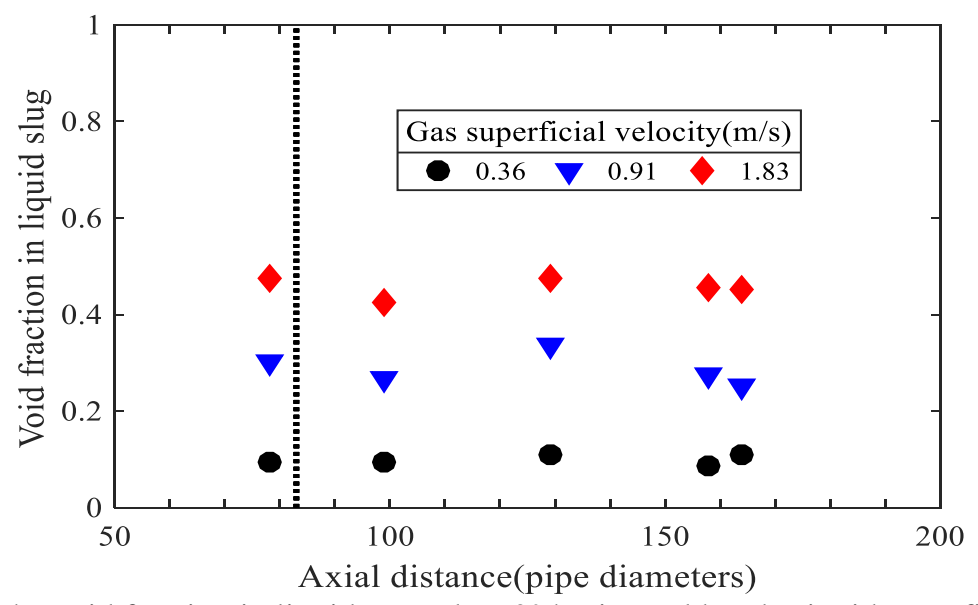

Fig. 4: Axial development of the void fraction in liquid around a $90^{\circ}$ horizontal bend. Liquid superficial velocity $=0.45 \mathrm{~m} \mathrm{~s}^{-1}$.

Fig. 5 illustrates the performance of gas holdup correlations at 5D upstream and 69D upstream of the bend. None of the applied correlations has shown a close agreement with the experimental results. All correlations have underestimated the gas holdup within the liquid slug at upstream and downstream of the bend. This is attributed to the fact that most of the used correlations are applicable to a limited range of flow conditions. The gas holdup of silicone oil used in this work is much higher than that reported for water. 


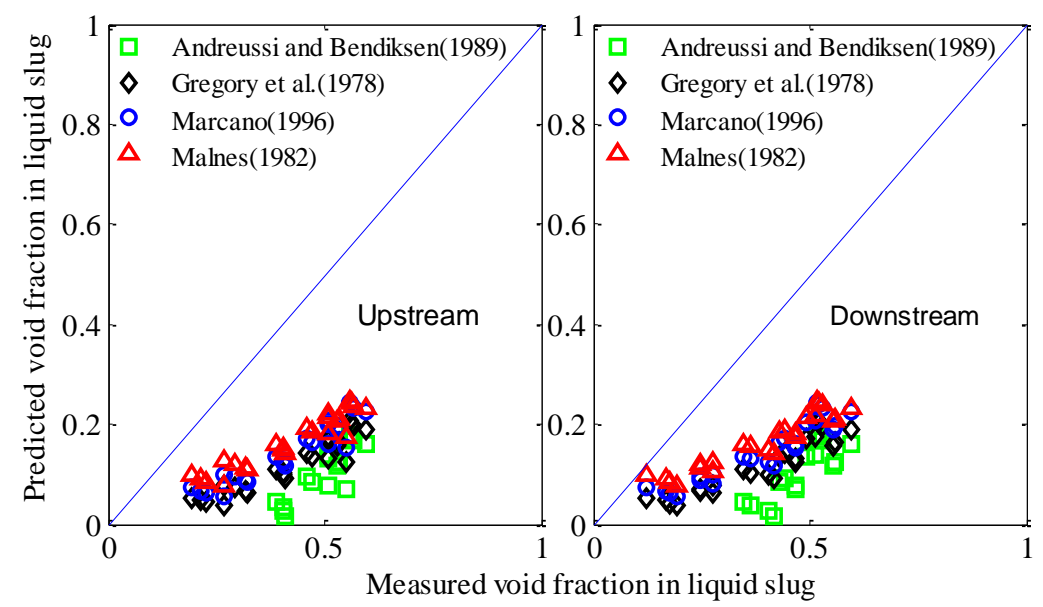

Fig. 5: Predicted void fraction in liquid slug at 5D before and 69D after the horizontal bend.

\subsection{Slug Frequency}

The slug frequency at upstream and downstream of a horizontal bend is estimated in order to evaluate the influence of the bend on the behaviour of liquid slugs at different gas and liquid superficial velocities. Fig. 6 illustrates the change in slug frequency and void fraction in the liquid slugs along the pipeline at different gas superficial velocities. Fig. 6 shows that beyond the bend the frequency seems to be independent of the axial position, particularly at high gas flow. The frequency of slugs also decreases with the increase of gas superficial velocity, however, at high gas flow rate the effect is less obvious and inconsistent.

At gas superficial velocity of $3.21 \mathrm{~m} . \mathrm{s}^{-1}$, the frequency downstream of the bend appears more arbitrary. The high gas flow is associated with low liquid layer and more waves; subsequently the formation mechanism of slugs is rather complicated. The shallow liquid layer is not sufficient to initiate slugs, although, waves may coalesce before or rarely after the bend and form highly aerated and mostly unstable slugs.

In general, the frequency decreases slightly after the bend. This small reduction in the frequency after the horizontal bend is a direct consequence of the dissipation of some slugs after the bend, along the pipeline. Occasionally, few developing slugs are destroyed at the bend, due to the direct impact with the outer wall of the bend. It is undoubtedly that the bend enhances the dissipation of the slugs due to momentum transfer and phase separation, although, as Fig. 6 suggested, the change in the axial position of the measurements might be another reason to consider.

It was noticed that the frequency is well correlated in term of Strouhal number as suggested first by [8]. Therefore the experimental frequency at 69D downstream of the bend was presented in term of the dimensionless Strouhal number against liquid volume fraction as reported by [9]. The parameters associated with the equation of Fossa et al. were slightly adjusted to fit the current results as in eq. (1):

$$
S t=\frac{\mathrm{f}_{\mathrm{s}} D}{u_{s g}}=\frac{0.04 X_{L}}{1-1.5 X_{L}+0.4\left(X_{L}\right)^{2}}
$$




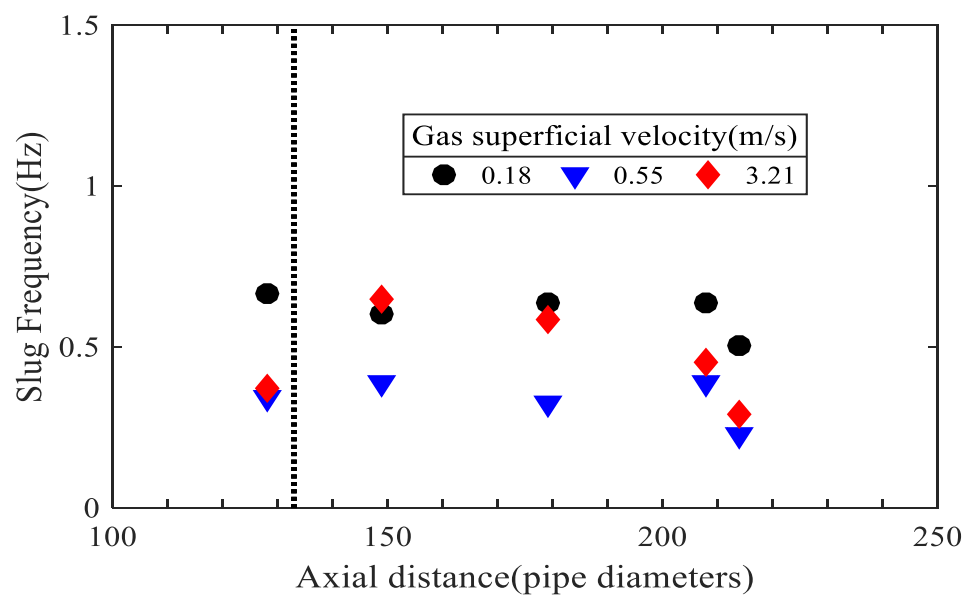

Fig. 6: Axial development of the slug frequency around a $90^{\circ}$ horizontal bend. Liquid superficial velocity $=0.45 \mathrm{~m} \mathrm{~s}^{-1}$.

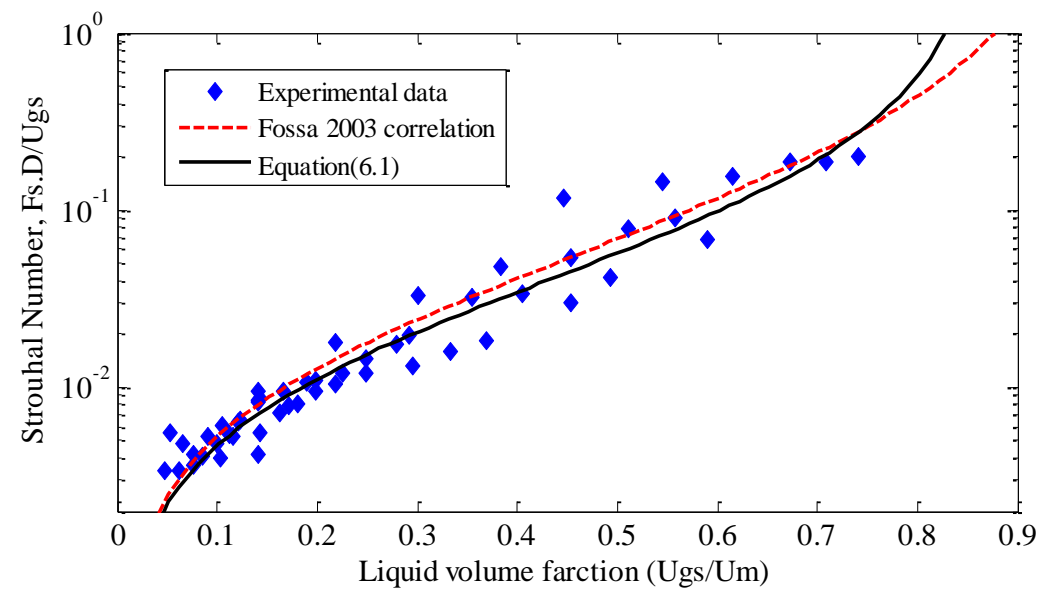

Fig. 7: Experimental slug frequency at 69D downstream of a horizontal bend is correlated in term of Strouhal number.

Fig. 7 shows a satisfactory agreement between the experimental results and the correlation of Fossa et al. and eq.(1), similar findings are reported by [10] and [11]. The frequency of slugs has been commonly correlated in term of pipe diameter and liquid superficial velocity, where a neglected change with axial position is suggested. This work ,in accordance with to Fossa et al. (2003), [10] and [11], indicates the frequency seems to be better correlated in term of Strouhal number as a function of liquid volume fraction. However, this approach needs to be tested against a wide range of experimental data before a final conclusion can be reached.

\subsection{Slug Bubble Velocity}

Slug velocity encountered a slight increase after the horizontal bend at the low gas superficial velocity, below $1.5 \mathrm{~m} \mathrm{~s}^{-}$ ${ }^{1}$. This is due to the gas expansion that is caused by the pressure drop after the bend. At high gas superficial velocity, the pressure drop increases across the bend and hence, the velocity of slug bubble notably increases. It is acknowledged that liquid slugs move at velocity equal to the gas velocity upstream while waves and undeveloped slugs travel at velocity almost 30\% lower than the velocity of gas flow [12]. The destruction of undeveloped slugs and dissipation of waves at the bend could increase the averaged velocity of slug structure predicted experimentally at downstream of the bend, due to the fact that undeveloped slugs travels at lower velocity than developed slugs.

Fig. 8 illustrates the comparison between the predicted and measured values of the gas bubble velocities. Nicklin, et al. [13] correlation demonstrated a good prediction of the transitional velocity of slug bubble, especially at low mixture velocity (Fig. 8). As the mixture velocity increases (Froude number> 3.5) the predicted values start to deviate from the 
measured values. The Gregory and Scott [14] correlation was found to underestimate the measured velocity at low gas and liquid velocities while the prediction improves at high mixture velocities. This indicates that the contribution of the drift velocity is negligible at high mixture velocities.

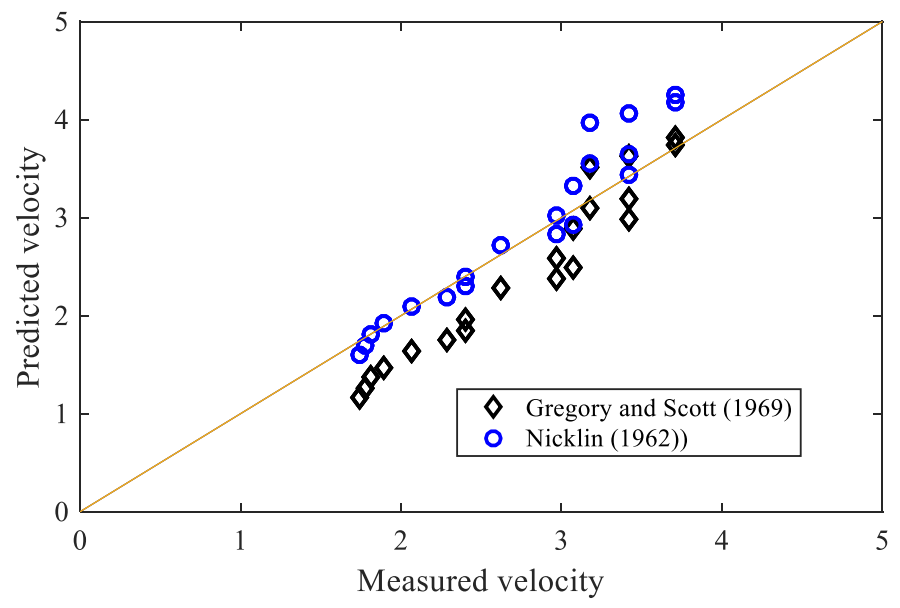

Fig. 8: Predicted slug bubble velocity at 69D downstream of the horizontal bend.

\section{Conclusion}

A detailed study of slug flow evolution around a horizontal to horizontal $90^{\circ}$ bend and downstream was conducted in an open system of $69 \mathrm{~mm}$ ID pipes. The axial development of slugs was investigated, in the horizontal sections after the bend, using WMS and ECT. The main observations of these experiments are concluded in the following points:

- Slug flow upstream of the bend is mainly generated due to growing waves; as described by the Kelvin-Helmholtz instability. At high gas superficial velocities $(>2.29 \mathrm{~m} . \mathrm{s}-1)$, the liquid layer becomes thinner than the required height to initiate slugs. At these conditions, slugs were evolved from the coalescence of roll waves travelling at different velocities.

- The horizontal bend has a minor influence on the frequency of liquid slugs. The destruction of low momentum slugs at the bend is the main cause of reduction in frequency at downstream of the bend.

- The frequency of slugs is well correlated in term of Strouhal number as a function of liquid volume fraction.

- The void fraction in liquid slug encountered an inconsiderable change around the horizontal bend. The gas holdup is observed to slightly increase after the bend, especially at low gas flows.

- The slugs seems to accelerate after the horizontal bend, possibly due to the gas expansion caused by the pressure drop at the bend. As the gas superficial velocity increases the effect of the bend becomes more evident.

- The horizontal $90^{\circ}$ bends have inconsiderable effects on the on the characteristics of liquid slugs. This is due to that the phase separation and momentum transfer being insignificant. The horizontal bend has a minimum influence on the velocity and frequency of the flow structure.

\section{Acknowledgements}

Rajab Omar would like to thank the Libyan government for the support provided to carry out this work.

\section{References}

[1] Y. Taitel and D. Barnea, "Two-phase slug flow," Advances in heat transfer, vol. 20, pp. 83-132, 1990.

[2] E. Al-Safran, C. Sarica, H. Q. Zhang, and J. Brill, "Investigation of slug flow characteristics in the valley of a hillyterrain pipeline," International Journal of Multiphase Flow, vol. 31, pp. 337-357, 2005.

[3] A. E. Dukler and M. G. Hubbard, "A model for gas-liquid slug flow in horizontal and near horizontal tubes," Industrial \& Engineering Chemistry Fundamentals, vol. 14, pp. 337-347, 1975.

[4] R. C. Fernandes, R. Semiat, and A. E. Dukler, "Hydrodynamic model for gas-liquid slug flow in vertical tubes," AIChE Journal, vol. 29, pp. 981-989, 1983. 
[5] T. J. Hanratty and A. Hershman, "Initiation of roll waves," AIChE Journal, vol. 7, pp. 488-497, 1961.

[6] O. J. Nydal, S. Pintus, and P. Andreussi, "Statistical characterization of slug flow in horizontal pipes," International Journal of Multiphase Flow, vol. 18, pp. 439-453, 1992.

[7] P. Y. Lin and T. J. Hanratty, "Effect of pipe diameter on flow patterns for air-water flow in horizontal pipes," International Journal of Multiphase Flow, vol. 13, pp. 549-563, 1987.

[8] R. M. Nedderman and C. J. Shearer, "The motion and frequency of large disturbance waves in annular two-phase flow of air-water mixtures," Chemical Engineering Science, vol. 18, pp. 661-670, 1963.

[9] M. Fossa, G. Guglielmini, and A. Marchitto, "Intermittent flow parameters from void fraction analysis," Flow Measurement and Instrumentation, vol. 14, pp. 161-168, 2003.

[10] X. Wang, L. Guo, and X. Zhang, "An experimental study of the statistical parameters of gas-liquid two-phase slug flow in horizontal pipeline," International Journal of Heat and Mass Transfer, vol. 50, pp. 2439-2443, 2007.

[11] M. Abdulkadir, V. Hernandez-Perez, I. S. Lowndes, B. J. Azzopardi, and E. Sam-Mbomah, "Experimental study of the hydrodynamic behaviour of slug flow in a horizontal pipe," Chemical Engineering Science, vol. 156, pp. 147$161,2016$.

[12] N. Andritsos, L. Williams, and T. J. Hanratty, "Effect of liquid viscosity on the stratified-slug transition in horizontal pipe flow," International Journal of Multiphase Flow, vol. 15, pp. 877-892, 1989.

[13] D. J. Nicklin, J. O. Wilkes, and J. F. Davidson, "Two-phase flow in vertical tubes," Transaction of Institution of Chemical Engineers, vol. 40, pp. 61-68, 1962.

[14] G. A. Gregory and D. S. Scott, "Correlation of liquid slug velocity and frequency in horizontal cocurrent gas-liquid slug flow," AIChE Journal, vol. 15, pp. 933-935, 1969. 